\title{
Partial pyrolysis of olive wood to improve its sorption of chlorophenols and nitrophenols
}

\author{
A. H. El-Sheikh
}

Received: 9 August 2012/Revised: 12 March 2013/Accepted: 6 May 2013/Published online: 25 May 2013

(C) Islamic Azad University (IAU) 2013

\begin{abstract}
Partial pyrolysis alters the chemical and textural properties of the lignocellulosic material. This work reports the effect of partial pyrolysis of olive wood on adsorption isotherms, kinetics and thermodynamics of chloro and nitrophenols. Shape of adsorption isotherms of the partially pyrolyzed sorbents was L3 for phenol; L2 for 2-nitrophenol and 2,4-dinitrophenol; H3 for 2-chlorophenol, 3-chlorophenol and 4-nitrophenol; and $\mathrm{H} 2$ for 4-chlorophenol. The pyrolyzed olive wood sorbents obeyed Langmuir and Freundlich models. Pyrolysis raised adsorption capacity, favorability and spontaneity; the adsorption became more exothermic; the randomness decreased. The adsorption was mainly physical; it occurred first by film diffusion then by pore-filling. Adsorption followed second-order rate kinetics. Adsorption of phenols on olive wood seemed to be governed by hydrophobic interaction. Washing the pyrolyzed olive wood with ethanol caused a decrease in adsorption capacity, favorability and spontaneity, and the adsorption became less exothermic. This indicated that pyrolysis produced species on the olive wood surface that played a significant role in phenols adsorption.
\end{abstract}

Keywords Adsorption models · Olive wood P Phenols · Pyrolysis

\section{Introduction}

Olive wood is considered an important agricultural waste product in the Mediterranean area. This is due to the

\footnotetext{
A. H. El-Sheikh $(\square)$

Department of Chemistry, Faculty of Science, Hashemite

University, Zarqa 13115, Jordan

e-mail: amjadelsheikh3@yahoo.com
}

widespread cultivation of olives and to huge amounts of wood produced from pruning process every year. Olive wood has many uses: an energy source, a sugar source for bioethanol production, and for the production of cellulose kraft pulp and activated carbon. Environmentalists have used olive waste materials for uptake of metal ions from aqueous solutions (de Hoces et al. 2006; Saka et al. 2012). Modification of lignocellulosic sorbents by physical and/or chemical methods may affect its chemical and textural properties.

For example, Shin et al. (2005) reported modification of lignocellulosic sorbents with lanthanum for orthophosphate treatment. Martin-Lara et al. (2008) reported modification of olive waste with phosphoric acid and hydrogen peroxide for improving adsorption of cupper and cadmium. Abia et al. (2003) reported modification of cassava waste biomass with thioglycolic acid to improve the adsorption of cadmium, copper and zinc. Raji and Amirudhan (1998) reported modification of sawdust with polyacrylamide for chromium (VI) adsorption. Igwe et al. (2005) reported carboxymethylation and thiolation of coconut fiber and sawdust for the adsorption of lead, mercury and arsenic ions in water. Zghida et al. (2006) reported the cationization of cotton fibers, wood sawdust and maize-cob flour for removing anionic surfactants from water.

Pyrolysis is a physical process which involves heating a carbonaceous material at high temperature under inert atmosphere. Pyrolysis was widely used for the preparation of activated carbon (El-Sheikh et al. 2004). If the lignocellulosic sorbent is heated at low temperature under inert atmosphere, this will partially change the chemical and textural characteristics of the sorbent without forming activated carbon. This is called partial pyrolysis.

Phenolic compounds are toxic compounds. Some are suspected human carcinogens (EPA 1988). They may 
present in the wastewater generated from paint, petrochemical, pharmaceutical, plastic, rubber proofing, pesticide, iron steel, phenol production, paper and pulp industries (Ahmaruzzaman 2008). Long-term exposure to them may cause loss of appetite, headache and rapid fatigue. United States Environmental Protection Agency called for lowering phenol content in wastewater to less than $1 \mathrm{mg} \mathrm{L}^{-1}$.

Traditionally, adsorption by activated carbon was the most efficient method for the removal of phenolic compounds from water. Recently, microorganisms have been considered promising biosorbents of phenols (Brandt et al. 1997). Various sorption processes may be involved: adsorption, ion exchange and covalent bonding (Fourest and Volesky 1997). Unfortunately, the use of microorganisms may cause fatal diseases. Alternatively, the use of agricultural waste material is safer and renewable. It also solves waste disposal problem. Sorption of phenols was reviewed by Ahmaruzzaman (2008) and by Mathialagan and Viraraghavan (2008). Sorption of phenol and 2-chlorophenol on Funalia trogii pellets was investigated by Bayramoglu et al. (2009). Vazquez et al. (2007) reported adsorption of phenol on formaldehyde-pretreated Pinus pinaster bark. Wu and Yu (2006) studied adsorption of 2,4dichlorophenol from aqueous solution on Phanerochaete chrysosporium biomass. This is in addition to many other works (Navarro et al. 2008; Aravindhan et al. 2009; Nadavala et al. 2009).

In adsorption studies, it is critical to investigate the shape of isotherms, equilibrium, kinetic and thermodynamic parameters of the adsorption process. This will help better understand the adsorption characteristics. Some researchers reported the kinetics of phenols adsorption on various biosorbents ( $\mathrm{Wu}$ and $\mathrm{Yu}$ 2006; Vazquez et al. 2007; Bayramoglu et al. 2009; Nadavala et al. 2009). Other works reported thermodynamics of phenols adsorption (Wu and Yu 2006; Aravindhan et al. 2009; Bayramoglu et al. 2009).

In this work, the effect of pyrolysis of olive wood at various temperatures on its adsorption properties toward seven phenolic compounds is investigated. The following chlorophenols and nitrophenols were selected because they have a wide range of $p K_{a}$ values: phenol: 9.89; 2-chlorophenol: 8.5; 3-chlorophenol: 8.8; 4-chlorophenol: 9.2; 2-nitrophenol: 7.17; 4-nitrophenol: 7.15; 2,4-dinitrophenol: 4.96. It is proposed that pyrolysis will change the surface chemistry and textural properties of the olive wood surface. While volatile components will be vaporized, chemical degradation of some constituents may also occur. So that further washing of the pyrolyzed sorbent may be necessary to uncover the pyrolyzed surface. This will elucidate the role of the compounds covering the pyrolyzed olive wood surface in the adsorption process. Parameters of Langmuir and Freundlich adsorption models, free energy of adsorption, kinetic and intraparticle diffusion parameters, and thermodynamic parameters $\left(\Delta G^{\circ}, \Delta H^{\circ}\right.$ and $\left.\Delta S^{\circ}\right)$ will be studied in this work. All experiments were conducted at $\mathrm{pH}$ 7 in this work because it was the optimum $\mathrm{pH}$ for solid phase extraction of those phenols on olive wood in our previous work (El-Sheikh et al. 2011). This work was done during the period from February to October 2010 at the department of chemistry/The Hashemite University/Zarqa/ Jordan.

\section{Materials and methods}

Chemicals and materials

Chemicals used in this work were purchased from the following resources: phenol $(\mathrm{Ph})$ from $\mathrm{POCH}$ (Poland); 2-chlorophenol (2-CP) and 4-chlorophenol (4-CP) from Fluka (Italy); 3-chlorophenol (3-CP) and 2,4-dinitrophenol (2,4-DNP) from ACROS (Belgium); 2-nitrophenol (2-NP) from Aldrich (Germany); 4-nitrophenol (4-NP) from Merck (Germany); ethanol and n-hexane from TEDIA (USA); and diethyl ether from Scharlau (Spain). Olive wood used in this work was collected from olive trees grown in Tareq area at the capital city Amman. Olive wood was cut into small pieces, ground with a blender and then passed through a $1.0 \mathrm{~mm}$ sieve. That was considered as the unpyrolyzed olive wood.

\section{Pyrolysis of olive wood}

The raw (unpyrolyzed) olive wood was used to prepare pyrolyzed olive wood; $10.0 \mathrm{~g}$ raw (unpyrolyzed) olive wood was placed inside a furnace under inert atmosphere $\left(\mathrm{N}_{2}\right.$ gas flowing at $8.0 \mathrm{~L} \mathrm{~min}^{-1}$ ). Pyrolysis was conducted at various temperatures: $100,150,200,250$ and $300{ }^{\circ} \mathrm{C}$. Pyrolysis was done by flowing $\mathrm{N}_{2}$ gas for $15 \mathrm{~min}$, and then the furnace was turned on and adjusted to the desired temperature. The temperature was maintained for $1 \mathrm{~h}$ after which the furnace was switched-off and $\mathrm{N}_{2}$ gas flow was maintained until furnace temperature reached room temperature.

For the sake of removing any compounds covering the pyrolyzed adsorbents' surface, the produced sorbents were washed. Washing pyrolyzed olive wood was conducted by agitating the pyrolyzed olive wood with $50 \mathrm{ml}$ of the desired solvent for $2 \mathrm{~h}$. The UV-VIS spectrum of the wash was recorded and the process was repeated several times until absorption spectrum was identical with that of the pure washing solvent. The washed-pyrolyzed sorbents were then dried at $150{ }^{\circ} \mathrm{C}$ to remove any traces of ethanol. The 
produced adsorbents were labeled according to the pyrolysis temperature followed by washing solvent. So that three sets of olive wood were used in this work:

(a) Unpyrolyzed olive wood (OW).

(b) Pyrolyzed only olive wood at various temperatures: raw unpyrolyzed olive wood, OW-100, OW-150, OW-200, OW-250 and OW-300.

(c) Pyrolyzed olive wood at various temperatures followed by ethanol washing: OW-100-ethanol, OW-150-ethanol, OW-200-ethanol, OW-250-ethanol and OW-300-ethanol.

\section{Equilibrium adsorption experiments}

Batch adsorption experiments were conducted for each phenolic compound separately to estimate the equilibrium adsorption parameters and thermodynamic constants for the adsorption of each phenolic compound on the unpyrolyzed and pyrolyzed olive wood sorbents. To reach this purpose, masses of $50 \mathrm{mg}$ of the adsorbent were mixed with $25 \mathrm{~mL}$ solutions of certain phenolic compound (concentration range $0-25 \mathrm{mg} \mathrm{L}^{-1}$ ) in 50-ml-conical flasks at $\mathrm{pH}$ 7.0. Tightly closed flasks were shaken for $24 \mathrm{~h}$ at 30,50 or $70{ }^{\circ} \mathrm{C}$ to reach equilibrium using a thermo-stated shaker (GFL 1083, Germany). The remaining concentrations of the phenolic compound at equilibrium $\left(C_{\mathrm{e}}\right)$ were estimated spectrometrically using a Cary 100Bio UV-VIS spectrophotometer at the following wavelength values: $\mathrm{Ph}$ : $270 \mathrm{~nm}$; 2-CP and 3-CP: $276 \mathrm{~nm}$; 4-CP: $282 \mathrm{~nm}$; 2-NP: $278 \mathrm{~nm}$; 4-NP: $316 \mathrm{~nm}$; 2,4-DNP: $354 \mathrm{~nm}$. The amount of the phenolic compound removed per unit mass of sorbent at equilibrium $\left(q_{\mathrm{e}}, \mathrm{mg} \mathrm{g}^{-1}\right)$ was calculated using the following equation:

$q_{\mathrm{e}}=\left[C_{\mathrm{o}}-C_{\mathrm{e}}\right] V / m$

where $C_{\mathrm{o}}$ is the initial phenolic compound concentration $\left(\mathrm{mg} \mathrm{L}^{-1}\right), V$ is the total volume of mixture (L), and $m$ is the mass of sorbent $(\mathrm{g})$.

\section{Batch kinetic experiments}

Kinetic adsorption experiments were conducted as follows: $500 \mathrm{mg}$ of the adsorbent was stirred at $30{ }^{\circ} \mathrm{C}$ with $500 \mathrm{~mL}$ solution of $15 \mathrm{mg} \mathrm{L}^{-1}$ of the desired phenolic compound at $\mathrm{pH}$ 7. The decay in phenolic compound concentration was followed by withdrawing $3 \mathrm{~mL}$ samples from the mixture using a pipette at certain time intervals $(t)$, and then the phenolic compound concentration at that time $\left(C_{t}\right)$ was determined spectrometrically as described in "Equilibrium adsorption experiments." The adsorbed amount of the phenolic compound on the adsorbent $\left(q_{t}\right)$ at time $t$ was estimated $\left(\mathrm{mg} \mathrm{g}^{-1}\right)$ using the equation:
$q_{t}=\left[C_{\mathrm{o}}-C_{t}\right] V / m$

Evaluation of adsorption data

\section{Equilibrium adsorption isotherm models}

Langmuir model Langmuir assumes that the surface is homogenous. The linear Langmuir equation may be written as follows (Langmuir 1918):

$\frac{C_{\mathrm{e}}}{q_{\mathrm{e}}}=\frac{1}{b Q_{\max }}+\frac{C_{\mathrm{e}}}{Q_{\max }}$

where $C_{\mathrm{e}}$ is the remaining concentration of phenolic compound at equilibrium in the solution $\left(\mathrm{mg} \mathrm{L}^{-1}\right), q_{\mathrm{e}}$ is the amount of phenolic compound adsorbed per unit mass of sorbent at equilibrium $\left(\mathrm{mg} \mathrm{g}^{-1}\right), Q_{\max }$ is the amount of adsorbate at complete monolayer coverage $\left(\mathrm{mg} \mathrm{g}^{-1}\right)$, and $b$ is the equilibrium adsorption constant $\left(\mathrm{L} \mathrm{mg}^{-1}\right)$, which represents the ratio of adsorption and desorption rate constants. Higher values of $b$ indicate more favorable adsorption. Evaluation of $Q_{\max }$ and $b$ was conducted by plotting $\left(C_{\mathrm{e}} / q_{\mathrm{e}}\right)$ against $C_{\mathrm{e}}$ and then linear regression.

Freundlich model Freundlich assumes heterogeneous surface. Freundlich isotherm model can be represented by the following linear equation (Freundlich 1906; Sanchez et al. 1999):

$\log q_{\mathrm{e}}=\log K_{\mathrm{F}}+n \log C_{\mathrm{e}}$

where $K_{\mathrm{F}}\left(\mathrm{mg}^{1-n} \mathrm{~g}^{-1} \mathrm{~L}^{n}\right)$ represents the sorption capacity when equilibrium concentration equals to 1 , and $n$ represents the degree of dependence of sorption on equilibrium concentration. $n$ is an indicator of sorption intensity, surface heterogeneity and adsorption favorability (Frimmel and Huber 1996). Lower values of $n$ reflect higher heterogeneity of the adsorbent surface and that sorption is favorable over the entire studied concentrations range (Frimmel and Huber 1996). Evaluation of $K_{\mathrm{F}}$ and $n$ values was conducted by plotting $\log q_{\mathrm{e}}$ against $\log C_{\mathrm{e}}$ and then linear regression.

\section{Kinetic parameters}

The adsorption kinetics of the phenolic compounds was evaluated by applying two kinetic models to fit the concentration decay of phenolic compounds with time: the pseudo-first-order model (Lagergren 1898) and pseudosecond-order model (Ho and Mckay 2000). The experimental value of $q_{\mathrm{e}}$ was estimated by extrapolating the experimental data to $t=\infty$.

Pseudo-first-order kinetics According to Lagergren (1898), pseudo-first-order kinetic equation may take the following linear form: 
$\log \left(q_{\mathrm{e}}-q_{t}\right)=\log q_{\mathrm{e}}-\left(k_{1} / 2.303\right) t$

where $q_{\mathrm{e}}$ and $q_{t}$ (both in $\mathrm{mg} \mathrm{g}^{-1}$ ) are the amounts of phenolic compounds adsorbed at equilibrium and at time $t$ (minutes), and $k_{1}$ is the pseudo-first-order rate constant $\left(\min ^{-1}\right) . k_{1}$ may be found by plotting $\log \left(q_{\mathrm{e}}-q_{t}\right)$ versus $t$ and then linear regression.

Pseudo-second-order kinetics The pseudo-second-order kinetics may be expressed using the following equation (Ho and Mckay 2000):

$t / q_{t}=\left(1 / k_{2} q_{\mathrm{e}}^{2}\right)+\left(1 / q_{\mathrm{e}}\right) t$

where $k_{2}\left(\mathrm{~g} \mathrm{mg}^{-1} \mathrm{~min}^{-1}\right)$ is the second-order rate constant of adsorption. The values of $k_{2}$ and $q_{\mathrm{e}}$ can be estimated experimentally from the slope and intercept of the plot $t / q_{t}$ versus $t$.

\section{Adsorption mechanism}

It is important in adsorption studies to understand whether adsorption occurs through chemisorption process or physicsorption process. This may be predicted by following the free energy of adsorption $(E)$. Furthermore, it is important to decide which step is the rate determining step: film diffusion or pore diffusion.

Free energy of adsorption (E) Free energy of adsorption $(E)\left(\mathrm{mol}^{2} \mathrm{~J}^{-2}\right)$ was estimated by applying Dubinin-Radushkevich model (Nadavala et al. 2009), which is represented by the following linear equation:

$\ln q_{\mathrm{e}}=\ln q_{m}-B \varepsilon^{2}$

where $\varepsilon=R T \ln \left(1+\left(1 / C_{\mathrm{e}}\right)\right) ; B$ is a constant that is related to $E\left(\mathrm{~J} \mathrm{~mol}^{-1}\right)$ where $E=(-2 B)^{-1 / 2}$ (Bansode et al. 2004); $R$ is the gas constant $\left(8.314 \mathrm{~J} \mathrm{~mol}^{-1} \mathrm{~K}^{-1}\right)$; and $T$ is the temperature (K). The values of $B$ were found by plotting $\ln q_{\mathrm{e}}$ against $\varepsilon^{2}$ and then linear regression. The adsorption mechanism may be predicted by following the value of $E$ : If $E$ is between 8 and $16 \mathrm{~kJ} \mathrm{~mol}^{-1}$, then the adsorption occurs mainly through chemisorption (ion exchange) process. If $E<8 \mathrm{~kJ} \mathrm{~mol}^{-1}$, then the adsorption process has mainly physical nature (Sanchez et al. 1999).

Intraparticle diffusion Kinetic data can be used to specify the mechanism of adsorption ( $\mathrm{Wu}$ and $\mathrm{Yu}$ 2006; Aravindhan et al. 2009). For solid-liquid adsorption, either film diffusion or intraparticle diffusion or both usually control the solute transfer process. The sorption rate will be generally controlled by the slowest step (Aravindhan et al. 2009). The intraparticle (pore) diffusion may be the ratelimiting step of the adsorption process. This may be confirmed by applying Morris-Weber equation (Weber and Morris 1963):

$q_{t}=k_{\mathrm{id}} \cdot t^{0.5}$

where $k_{\mathrm{id}}$ is the intraparticle transport constant ( $\mathrm{mg} \mathrm{g} \mathrm{min}{ }^{-1 / 2}$ ) of the phenolic compound. If a straight line passing through the origin is obtained, then the intraparticle diffusion is the only rate-limiting step. If biphasic plot is obtained, film diffusion (first linear portion of the plot usually of steeper slope) occurs first and then pore diffusion (second linear portion of the plot usually of lower slope) follows. The slope of the second portion represents $k_{\mathrm{id}}$.

\section{Thermodynamic parameters}

Thermodynamic properties of the adsorption system were estimated by conducting the sorption experiments at different temperatures $\left(30,50\right.$ and $\left.70{ }^{\circ} \mathrm{C}\right)$. The effect of temperature on adsorption of various phenolic compounds on olive wood-based adsorbents was studied by applying the following equations:

In $K_{\mathrm{c}}=\left(-\Delta H^{\circ} / R T\right)+\left(\Delta S^{\circ} / R\right)$ and $\Delta G^{\circ}=-R T \ln K_{c}$

where $\Delta H^{\circ} \quad\left(\mathrm{kJ} \mathrm{mol}^{-1}\right), \quad \Delta S^{\circ} \quad\left(\mathrm{kJ} \mathrm{mol}^{-1} \mathrm{~K}^{-1}\right), \quad \Delta G^{\circ}$ $\left(\mathrm{kJ} \mathrm{mol}^{-1}\right), T(\mathrm{~K})$ and $K_{\mathrm{c}}$ are enthalpy, entropy, Gibbs free energy, absolute temperature and equilibrium constant, respectively, $R$ is the gas constant $\left(8.314 \mathrm{~J} \mathrm{~mol}^{-1} \mathrm{~K}^{-1}\right)$, and $K_{c}$ is the thermodynamic equilibrium constant which reflects the ability and capacity of the adsorbent to retain the phenolic compound. This constant is determined by plotting $\ln \left(q_{\mathrm{e}} / C_{\mathrm{e}}\right)$ against $q_{\mathrm{e}}$ and extrapolating to $q_{\mathrm{e}}=0$ (Khan and Singh 1987). $\Delta G^{\circ}$ reflects the adsorption spontaneity. It also indicates that physical adsorption is taking place if $\Delta G^{\circ}$ ranges from -20 to $0 \mathrm{~kJ} \mathrm{~mol}^{-1}$ or chemisorption is taking place if $\Delta G^{\circ}$ ranges from -80 to $-400 \mathrm{~kJ} \mathrm{~mol}^{-1}$. By plotting $\ln K_{\mathrm{c}}$ against $(1 / T)$, straight lines were obtained from which $\Delta H^{\circ}$ and $\Delta S^{\circ}$ were calculated from the slope and intercept of the plots, respectively. The value of $\Delta H^{\circ}$ reflects the enthalpy of the reaction (exothermic or endothermic reaction). The value of $\Delta S^{\circ}$ reflects the change in randomness and disorder of the adsorption process.

\section{Results and discussion}

Characteristics of unpyrolyzed and pyrolyzed olive wood

The purpose of the present work is to study the effect of partial pyrolysis of olive wood on its kinetic, thermodynamic and equilibrium adsorption properties toward chlorophenols and nitrophenols. This is based on the hypothesis that pyrolysis alters the chemical composition of the olive 
wood by forcing chemical degradation of the olive wood. This may produce new compounds that play role or retard the adsorption process. It was shown in a previous work (El-Sheikh et al. 2011) that olive wood contains $6.9 \%$ moisture; $1.8 \%$ hemicelluloses; $42.0 \% \alpha$-cellulose; $44.0 \%$ lignin; $1.4 \%$ ash content; $49.9 \% \mathrm{C}$; and $44.0 \% \mathrm{O}$. After pyrolysis: the carbon content has increased and the oxygen content has decreased due to significant loss of volatile compounds and water. Almost $63 \%$ of the OW mass was lost after pyrolysis at $300{ }^{\circ} \mathrm{C}$ (El-Sheikh et al. 2011).

Pyrolysis will surely affect the chemical and structural properties of the olive wood. It was reported by Hajaligol et al. (2002) that the temperature range $\left(250-400{ }^{\circ} \mathrm{C}\right)$ is responsible for primary decomposition (thermolysis) of the lignocellulosic material. Bridgwater (1994) reported that cellulose degradation starts at $200{ }^{\circ} \mathrm{C}$ by $\beta$-elimination of the cellulose hydroxyl groups. The IR spectra showed a significant decrease in $\mathrm{O}-\mathrm{H}$ stretching band peak height at $200{ }^{\circ} \mathrm{C}$. This indicated loss of water originally adsorbed or formed by $\beta$-elimination. As temperature increases, the symmetrical and asymmetrical stretching of etheric group at $\sim 1,240$, 1,160 and $1,050 \mathrm{~cm}^{-1}$ disappeared, which indicate further destruction of cellulose. At higher temperatures, random bond cleavage of cellulose caused formation of low molecular weight compounds. Bridgwater (1994) reported that the production of volatile compounds ends at $450{ }^{\circ} \mathrm{C}$ and aromatization reactions start forming carbon. However, in this work, it was aimed not to allow the formation of carbon. According to Bridgwater (1994), degradation of hemicellulose starts by decomposition of the polymeric chain into water-soluble fragments, then to monomeric units and then into volatile compounds. This occurs between 220 and $320{ }^{\circ} \mathrm{C}$. Unfortunately, in our study, we could not support this hypothesis by IR data. The degradation of lignin starts by breaking aliphatic bonds to release tar hydrocarbon compounds (Bridgwater 1994). Secondary reactions (cracking and polymerization) then take place. This was indicated by the appearance of the $\mathrm{C}=\mathrm{C}$ stretching of symmetrical conjugated diene band at $1,620-1,625 \mathrm{~cm}^{-1}$ at $250{ }^{\circ} \mathrm{C}$. Not only will the chemical properties be affected, but also the textural properties. Grioui et al. (2007) reported that pyrolysis increases the porosity of the pyrolyzed lignocellulosic sorbents especially in the range $250-275{ }^{\circ} \mathrm{C}$. However, in our previous work (El-Sheikh et al. 2011), we have reported that the methylene blue relative surface area has decreased after pyrolysis. It was reported that olive wood may contain variety of compounds, such as hydroxytyrosol, tyrosol, cycloolivil, 7-deoxyloganic acid, oleuropein and ligstroside (Perez-Bonilla et al. 2006). The presence of some metals (alkali, earth alkaline and transition metals) in the olive wood may due to the decomposition of these compounds totally or partially. So that gaseous products such as $\mathrm{CO}_{2}, \mathrm{CO}, \mathrm{H}_{2}$, $\mathrm{C}_{2} \mathrm{H}_{2}, \mathrm{C}_{2} \mathrm{H}_{4}$ and $\mathrm{C}_{2} \mathrm{H}_{6}$ (Overend and Chornet 1999) may be elevated, and thus, porosity of the olive wood may be affected. It was also shown (El-Sheikh et al. 2011) that pyrolysis increased the surface acidity but decreased the surface basicity. This may reflect negligible responsibility of the textural properties and surface area toward phenols adsorption. On the contrary, the surface functional groups probably play the major role in phenols adsorption.

Equilibrium adsorption isotherms of phenols on olive wood

\section{Unpyrolyzed olive wood}

From the adsorption data presented in Table 1, adsorption of various phenols on unpyrolyzed olive wood was best represented by Fruendlich isotherm model as indicated by $R^{2}>0.9755$, while Langmuir isotherm model gave $R^{2}$ between 0.4921 and 0.8903 . The adsorption was favored over the entire concentration range and the surface was heterogeneous and the energy of the active sites was variable as indicated by $n$ values less than 1 (Frimmel and Huber 1996). The values of mean free energy of adsorption of unpyrolyzed olive wood $(E)$ are shown in Table 1 . They were in the range $2,236-2,887 \mathrm{~J} \mathrm{~mol}^{-1}$. This indicated the physical nature for the adsorption of all the phenols on unpyrolyzed olive wood (Sanchez et al. 1999).

\section{Pyrolyzed olive wood}

From Table 1, it was generally noted that Freundlich model best represented adsorption of $\mathrm{Ph}, 2-\mathrm{NP}$ and 2,4-DNP on pyrolyzed olive wood, while Langmuir model best represented adsorption of 2-CP, 3-CP, 4-CP and 4-NP on pyrolyzed olive wood. From $K_{F}$ values, it was noted that thermal treatment has almost doubled adsorption capacity of the olive wood. Pan and Xing (2008) reported that when H-bonds are predominant, a decrease in the oxygen-containing groups on the adsorbent surface would decrease the adsorption. This will offer less polar-polar and ionexchange type interaction with phenols. This will inhibit adsorption of more polar phenolic compounds. On the other hand, for adsorption controlled by hydrophobic interactions, the decrease in oxygen content would increase the accessibility and affinity of phenols toward the less polar surface. So that adsorption of phenols on olive wood seemed to be governed by hydrophobic interaction.

Surface heterogeneity, variability in active sites and favorability of adsorption at the entire concentration range are still predominant as indicated by $n$ values less than 1 . The adsorption became more favored since $b$ values have increased after pyrolysis. It was generally noted that the adsorption capacity ( $K_{F}$ values) and favorability ( $b$ values) of chlorophenols are higher than those of nitrophenols. 
Table 1 Parameters of adsorption isotherms of various phenols on unpyrolyzed and pyrolyzed olive wood sorbents

\begin{tabular}{|c|c|c|c|c|c|c|c|c|}
\hline & \multirow[t]{2}{*}{ Type } & \multirow[t]{2}{*}{$E\left(\mathrm{~J} \mathrm{~mol}^{-1}\right)$} & \multicolumn{3}{|c|}{ Langmuir model } & \multicolumn{3}{|l|}{ Freundlich model } \\
\hline & & & $b\left(\mathrm{~L} \mathrm{mg}^{-1}\right)$ & $Q_{\max }\left(\mathrm{mg} \mathrm{g}^{-1}\right)$ & $R^{2}$ & $K_{F}\left(\mathrm{mg}^{1-\mathrm{n}} \mathrm{g}^{-1} \mathrm{mg} \mathrm{L}^{\mathrm{n}}\right)$ & $n$ & $R^{2}$ \\
\hline \multicolumn{9}{|l|}{$\mathrm{Ph}$} \\
\hline Unpyrolyzed & L3 & 2,236 & 0.18 & 7.6 & 0.6567 & 1.2 & 0.63 & 0.9878 \\
\hline OW-100 & L3 & 2,500 & 0.27 & 8.5 & 0.8128 & 1.7 & 0.56 & 0.9783 \\
\hline OW-150 & L3 & 3,162 & 0.30 & 8.1 & 0.8007 & 1.8 & 0.52 & 0.9808 \\
\hline OW-200 & L3 & 2,500 & 0.24 & 8.4 & 0.7857 & 1.6 & 0.58 & 0.9782 \\
\hline OW-250 & L3 & 2,887 & 0.28 & 8.1 & 0.8039 & 1.7 & 0.54 & 0.9850 \\
\hline OW-300 & L3 & 2,673 & 0.27 & 8.2 & 0.7848 & 1.7 & 0.55 & 0.9755 \\
\hline \multicolumn{9}{|l|}{$2-\mathrm{CP}$} \\
\hline Unpyrolyzed & L1 & 2,236 & 0.14 & 12.8 & 0.7734 & 1.5 & 0.72 & 0.9971 \\
\hline OW-100 & H3 & 2,887 & 1.04 & 8.8 & 0.9634 & 3.4 & 0.51 & 0.8794 \\
\hline OW-150 & H3 & 2,673 & 0.84 & 9.0 & 0.9513 & 3.2 & 0.52 & 0.8350 \\
\hline OW-200 & H3 & 2,500 & 0.75 & 8.9 & 0.9520 & 3.0 & 0.53 & 0.8396 \\
\hline OW-250 & H3 & 2,887 & 0.94 & 8.6 & 0.9604 & 3.2 & 0.51 & 0.8594 \\
\hline OW-300 & $\mathrm{H} 3$ & 2,673 & 0.78 & 8.9 & 0.9506 & 3.1 & 0.53 & 0.8298 \\
\hline \multicolumn{9}{|l|}{$3-\mathrm{CP}$} \\
\hline Unpyrolyzed & L1 & 2,887 & 0.27 & 10.6 & 0.8903 & 2.0 & 0.62 & 0.9978 \\
\hline OW-100 & $\mathrm{H} 3$ & 3,536 & 1.43 & 8.6 & 0.9666 & 3.7 & 0.47 & 0.9149 \\
\hline OW-150 & H3 & 2,887 & 1.06 & 8.8 & 0.9624 & 3.5 & 0.50 & 0.8519 \\
\hline OW-200 & $\mathrm{H} 3$ & 2,887 & 0.97 & 8.6 & 0.9611 & 3.3 & 0.50 & 0.8454 \\
\hline OW-250 & $\mathrm{H} 3$ & 3,536 & 1.24 & 8.5 & 0.9660 & 3.5 & 0.48 & 0.8771 \\
\hline OW-300 & H3 & 2,887 & 1.00 & 8.7 & 0.9618 & 3.4 & 0.50 & 0.8395 \\
\hline \multicolumn{9}{|l|}{ 4-CP } \\
\hline Unpyrolyzed & L1 & 2,887 & 0.26 & 12.1 & 0.8717 & 2.2 & 0.65 & 0.9933 \\
\hline OW-100 & $\mathrm{H} 2$ & 3,162 & 1.15 & 11.1 & 0.9877 & 4.8 & 0.59 & 0.9107 \\
\hline OW-150 & $\mathrm{H} 2$ & 2,887 & 0.97 & 11.3 & 0.9726 & 4.6 & 0.61 & 0.8783 \\
\hline OW-200 & $\mathrm{H} 2$ & 2,887 & 0.80 & 11.6 & 0.9239 & 4.3 & 0.61 & 0.8525 \\
\hline OW-250 & $\mathrm{H} 2$ & 3,162 & 1.11 & 11.1 & 0.9736 & 4.7 & 0.58 & 0.8868 \\
\hline OW-300 & $\mathrm{H} 2$ & 2,887 & 0.88 & 11.6 & 0.9390 & 4.5 & 0.61 & 0.8516 \\
\hline \multicolumn{9}{|l|}{$2-\mathrm{NP}$} \\
\hline Unpyrolyzed & L4 & 2,236 & 0.10 & 6.1 & 0.6765 & 0.7 & 0.59 & 0.9755 \\
\hline OW-100 & $\mathrm{L} 2$ & 5,000 & 0.27 & 5.9 & 0.9065 & 1.2 & 0.52 & 0.9797 \\
\hline OW-150 & $\mathrm{L} 2$ & 2,500 & 0.28 & 5.8 & 0.9074 & 1.2 & 0.52 & 0.9773 \\
\hline OW-200 & $\mathrm{L} 2$ & 2,357 & 0.27 & 5.8 & 0.9026 & 1.2 & 0.53 & 0.9799 \\
\hline OW-250 & L2 & 2,673 & 0.29 & 5.7 & 0.9088 & 1.3 & 0.50 & 0.9812 \\
\hline OW-300 & L2 & 2,500 & 0.29 & 5.7 & 0.9014 & 1.2 & 0.51 & 0.9788 \\
\hline \multicolumn{9}{|l|}{ 4-NP } \\
\hline Unpyrolyzed & $\mathrm{L} 1$ & 2,236 & 0.078 & 17.2 & 0.4921 & 1.2 & 0.81 & 0.9825 \\
\hline OW-100 & H3 & 2,357 & 0.61 & 9.4 & 0.9573 & 2.9 & 0.57 & 0.8849 \\
\hline OW-150 & H3 & 2,357 & 0.55 & 9.5 & 0.9439 & 2.8 & 0.58 & 0.8686 \\
\hline OW-200 & H3 & 2,236 & 0.49 & 9.5 & 0.9359 & 2.6 & 0.59 & 0.8641 \\
\hline OW-250 & $\mathrm{H} 3$ & 2,500 & 0.54 & 9.4 & 0.9538 & 2.7 & 0.59 & 0.8888 \\
\hline OW-300 & H3 & 2,357 & 0.50 & 9.7 & 0.9554 & 2.6 & 0.60 & 0.8901 \\
\hline \multicolumn{9}{|l|}{ 2,4-DNP } \\
\hline Unpyrolyzed & L4 & 2,236 & 0.094 & 6.1 & 0.6430 & 0.7 & 0.62 & 0.9803 \\
\hline OW-100 & $\mathrm{L} 2$ & 5,000 & 0.26 & 5.8 & 0.9011 & 1.2 & 0.53 & 0.9741 \\
\hline OW-150 & $\mathrm{L} 2$ & 2,357 & 0.27 & 5.8 & 0.9015 & 1.2 & 0.53 & 0.9680 \\
\hline OW-200 & $\mathrm{L} 2$ & 2,887 & 0.26 & 5.7 & 0.8859 & 1.2 & 0.50 & 0.9814 \\
\hline OW-250 & $\mathrm{L} 2$ & 2,673 & 0.29 & 5.6 & 0.8944 & 1.2 & 0.49 & 0.9692 \\
\hline OW-300 & L2 & 2,673 & 0.28 & 5.6 & 0.8784 & 1.2 & 0.49 & 0.9661 \\
\hline
\end{tabular}


Table 2 Parameters of adsorption isotherms of pyrolyzed-ethanol-washed olive wood sorbents

\begin{tabular}{|c|c|c|c|c|c|c|c|c|}
\hline & \multirow[t]{2}{*}{ Type } & \multirow[t]{2}{*}{$E\left(\mathrm{~J} \mathrm{~mol}^{-1}\right)$} & \multicolumn{3}{|c|}{ Langmuir model } & \multicolumn{3}{|l|}{ Freundlich model } \\
\hline & & & $\overline{b\left(\mathrm{~L} \mathrm{mg}^{-1}\right)}$ & $Q_{\max }\left(\mathrm{mg} \mathrm{g}^{-1}\right)$ & $R^{2}$ & $K_{F}\left(\mathrm{mg}^{1-\mathrm{n}} \mathrm{g}^{-1} \mathrm{mg} \mathrm{L}^{\mathrm{n}}\right)$ & $n$ & $R^{2}$ \\
\hline \multicolumn{9}{|l|}{$\mathrm{Ph}$} \\
\hline OW-100-ethanol & L1 & 3,162 & 0.24 & 7.5 & 0.8187 & 1.3 & 0.51 & 0.9896 \\
\hline OW-150-ethanol & L1 & 2,673 & 0.22 & 7.6 & 0.810 & 1.3 & 0.58 & 0.9849 \\
\hline OW-200-ethanol & L1 & 4,082 & 0.18 & 8.0 & 0.7636 & 1.4 & 0.52 & 0.9190 \\
\hline OW-250-ethanol & L1 & 4,082 & 0.20 & 7.9 & 0.7916 & 1.4 & 0.52 & 0.9253 \\
\hline OW-300-ethanol & L1 & 2,887 & 0.23 & 7.5 & 0.8265 & 1.5 & 0.50 & 0.9368 \\
\hline \multicolumn{9}{|l|}{$2-\mathrm{CP}$} \\
\hline OW-100-ethanol & L1 & 2,887 & 0.20 & 10.8 & 0.7835 & 1.7 & 0.57 & 0.9448 \\
\hline OW-150-ethanol & L1 & 2,500 & 0.18 & 11.3 & 0.7973 & 1.7 & 0.65 & 0.9814 \\
\hline OW-200-ethanol & L1 & 3,162 & 0.11 & 14.0 & 0.6832 & 1.4 & 0.74 & 0.9780 \\
\hline OW-250-ethanol & L1 & 3,536 & 0.13 & 12.9 & 0.7503 & 1.5 & 0.71 & 0.9809 \\
\hline OW-300-ethanol & L1 & 2,357 & 0.15 & 12.1 & 0.7765 & 1.6 & 0.68 & 0.9817 \\
\hline \multicolumn{9}{|l|}{$3-\mathrm{CP}$} \\
\hline OW-100-ethanol & $\mathrm{L} 1$ & 2,887 & 0.24 & 10.4 & 0.8227 & 1.8 & 0.57 & 0.9611 \\
\hline OW-150-ethanol & $\mathrm{L} 1$ & 2,673 & 0.22 & 10.6 & 0.8128 & 1.7 & 0.65 & 0.9854 \\
\hline OW-200-ethanol & $\mathrm{L} 1$ & 4,082 & 0.15 & 12.0 & 0.7434 & 1.6 & 0.67 & 0.9778 \\
\hline OW-250-ethanol & $\mathrm{L} 1$ & 5,000 & 0.18 & 11.4 & 0.7929 & 1.6 & 0.66 & 0.9834 \\
\hline OW-300-ethanol & L1 & 2,673 & 0.19 & 11.1 & 0.7977 & 1.7 & 0.64 & 0.9799 \\
\hline \multicolumn{9}{|l|}{$4-\mathrm{CP}$} \\
\hline OW-100-ethanol & $\mathrm{L} 1$ & 4,082 & 0.26 & 11.4 & 0.7199 & 2.2 & 0.56 & 0.9497 \\
\hline OW-150-ethanol & L1 & 3,162 & 0.23 & 11.9 & 0.7038 & 2.1 & 0.61 & 0.9631 \\
\hline OW-200-ethanol & $\mathrm{L} 1$ & 5,000 & 0.16 & 13.5 & 0.6221 & 1.8 & 0.65 & 0.9658 \\
\hline OW-250-ethanol & L1 & 7,071 & 0.21 & 12.1 & 0.6617 & 2.1 & 0.58 & 0.9543 \\
\hline OW-300-ethanol & L1 & 3,536 & 0.21 & 12.1 & 0.6756 & 2.1 & 0.60 & 0.9588 \\
\hline \multicolumn{9}{|l|}{ 2-NP } \\
\hline OW-100-ethanol & $\mathrm{L} 4$ & 2,236 & 0.22 & 4.4 & 0.8737 & 0.82 & 0.52 & 0.9625 \\
\hline OW-150-ethanol & L4 & 2,236 & 0.24 & 4.3 & 0.8803 & 0.85 & 0.53 & 0.9647 \\
\hline OW-200-ethanol & L4 & 4,082 & 0.18 & 4.5 & 0.8621 & 0.80 & 0.53 & 0.9648 \\
\hline OW-250-ethanol & L4 & 4,082 & 0.20 & 4.5 & 0.8735 & 0.86 & 0.52 & 0.9640 \\
\hline OW-300-ethanol & L4 & 2,236 & 0.22 & 4.4 & 0.8754 & 0.89 & 0.50 & 0.9654 \\
\hline \multicolumn{9}{|l|}{ 4-NP } \\
\hline OW-100-ethanol & L1 & 2,357 & 0.15 & 11.6 & 0.7757 & 1.4 & 0.71 & 0.9774 \\
\hline OW-150-ethanol & L1 & 2,236 & 0.13 & 12.6 & 0.7211 & 1.3 & 0.76 & 0.9777 \\
\hline OW-200-ethanol & L1 & 3,162 & 0.10 & 14.2 & 0.5842 & 1.3 & 0.70 & 0.9646 \\
\hline OW-250-ethanol & L1 & 3,162 & 0.11 & 14.0 & 0.6712 & 1.3 & 0.75 & 0.9680 \\
\hline OW-300-ethanol & L1 & 2,236 & 0.12 & 13.1 & 0.7672 & 1.4 & 0.74 & 0.9752 \\
\hline \multicolumn{9}{|l|}{ 2,4-DNP } \\
\hline OW-100-ethanol & L4 & 2,236 & 0.20 & 4.5 & 0.8899 & 0.75 & 0.58 & 0.9788 \\
\hline OW-150-ethanol & L4 & 2,236 & 0.21 & 4.4 & 0.8766 & 0.77 & 0.56 & 0.9716 \\
\hline OW-200-ethanol & L4 & 4,082 & 0.17 & 4.5 & 0.8788 & 0.76 & 0.55 & 0.9625 \\
\hline OW-250-ethanol & L4 & 4,082 & 0.20 & 4.4 & 0.8862 & 0.83 & 0.52 & 0.9607 \\
\hline OW-300-ethanol & L4 & 2,236 & 0.20 & 4.4 & 0.8734 & 0.84 & 0.52 & 0.9635 \\
\hline
\end{tabular}

This was due to the fact that olive wood surface is negatively charged at $\mathrm{pH} 7$ since its point of zero charge was in the range 5-7 (El-Sheikh et al. 2011). Since nitrophenols are more acidic (less $p K_{a}$ values), then they will produce more phenolate anions at $\mathrm{pH} 7$, and more repulsion with the olive wood surface occurred. In case of nitrophenols, 2-NP and 2,4-DNP gave lower $K_{F}$ and $Q_{\max }$ values than 4-NP. This is probably due to the intramolecular hydrogen 
bonding between the phenolic hydrogen and the oxygen of the nitro substituent in the ortho position. This makes the phenolic proton of 2-NP less available for interaction with the surface functional groups (El-Sheikh et al. 2011).

The adsorption capacities of the pyrolyzed olive wood sorbents toward phenols were comparable to some values reported by Aravindhan et al. (2009), such as sawdustbased activated carbon: $2.82 \mathrm{mg} \mathrm{g}^{-1}$, and olive pomace: $5 \mathrm{mg} \mathrm{g}^{-1}$. Free energy of adsorption $(E)$ has generally increased after pyrolysis at almost all pyrolysis temperatures for all the phenols (see Table 1). However, all $E$ values indicated physical adsorption was taking place. However, values reported for $E$ in our work were lower than $E$ values $\left(12.5 \mathrm{~kJ} \mathrm{~mol}^{-1}\right)$ reported by Nadavala et al. (2009) for the adsorption of phenol on chitosan.

\section{Ethanol washing of the pyrolyzed olive wood on the adsorption process}

Pyrolysis of olive wood is expected to change the chemistry of the olive wood surface and may produce new species on the olive wood surface. These species may be adsorbed on the olive wood surface and may play a significant role in the adsorption process; they may enhance or inhibit the adsorption process. So that it was proposed that removing these species will affect the adsorption process positively or negatively depending on the role of these species in the adsorption process. Washing olive wood was conducted primarily to investigate the role of those species. Ethanol was selected for the washing process; it has a polarity index of $P^{1}=4.3$. Adsorption parameters are given in Table 2, from which it was noted that Freundlich model $\left(R^{2}>0.9190\right)$ represented the data better than Langmuir model $\left(0.5842<R^{2}<0.8899\right)$. Compared to pyrolyzed only sorbents (OW-100, OW-150, OW-200, OW-250, OW300 ), it was noted that $K_{F}$ values have decreased after washing the pyrolyzed olive wood with ethanol. This indicated that the washed-up species that were produced by the pyrolysis process and adsorbed on olive wood surface played a significant role in the adsorption process of phenols. Removal of these species by washing has negatively affected the adsorption process. This was also supported by noting that $b$ values have decreased after washing, which reflected a decrease in the adsorption favorability. $n$ values still $<1$, which reflected heterogeneous surface. Free energy of adsorption $(E)$ did not show clear trend after ethanol washing. However, values of $E$ indicated that the adsorption still has physical nature.

\section{Shape of adsorption isotherms}

The adsorption isotherms of the phenolic compounds on unpyrolyzed, pyrolyzed, and pyrolyzed-then-washed olive

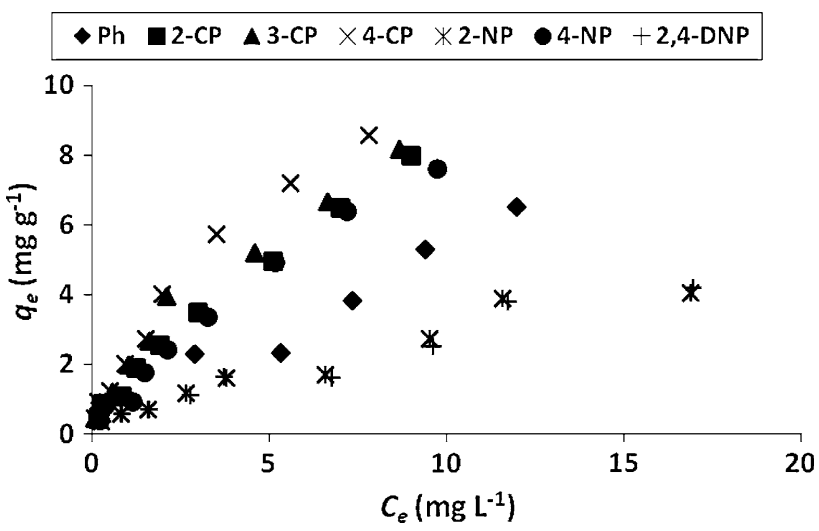

Fig. 1 Adsorption isotherms of various phenolic compounds on unpyrolyzed olive wood

wood adsorbents are shown in Figs. 1, 2 and 3. Classification of the isotherm types is presented in Tables 1 and 2 . The adsorption isotherms of phenolic compounds on unpyrolyzed olive wood were all of L-type according to Giles and Smith (1974) classification. After pyrolysis, adsorption isotherms of 2-CP, 3-CP, 4-CP and 4-NP became of $\mathrm{H}$-type, while $\mathrm{Ph}, 2-\mathrm{NP}$ and 2,4-DNP maintained L-type isotherms. Washing after pyrolysis gave L-type isotherm for almost all the phenols according to Giles and Smith (1974) classification. L shape is considered the normal isotherm shape, which indicates that molecules adsorbed flat on the surface. $\mathrm{H}$ curve is a special case of the $\mathrm{L}$ curve, in which the solute has such high affinity so that in dilute solutions, it is completely adsorbed. The subgroups of these classes are arranged according to the shape of the curve part farther from the origin and the significance of plateau and changes of slope (Giles and Smith 1974). L2 and H2 curves indicate that as more sites in the substrate are filled, it becomes more difficult for solute molecules to find an empty available site. In L2 and $\mathrm{H} 2$ curves, the adsorbed solute molecules in the monolayer are so oriented that the new surface they present to the solution has low attraction for solute molecules (Giles and Smith 1974). This is reflected by the plateau in L2 and $\mathrm{H} 2$ curves, which represents first-degree saturation or complete monolayer coverage. If they are so oriented that the new surface has high attraction for more solute, then the curve rises steadily and has no plateau (L1). That was the case for 2-CP, 3-CP, 4-CP, 4-NP on unpyrolyzed olive wood and for almost all phenols on pyrolyzed-then-ethanol-washed olive wood sorbents. If new surface is developed, adsorption will continue until a second plateau is developed (L or H4shapes), which represents the new saturation of the new surface. L4-shape was recorded for 2-NP and 2,4-DNP on unpyrolyzed olive wood and for 2-NP on pyrolyzed-thenethanol-washed olive wood. If second saturation is not reached, then the curve appears as L3 or H3 shapes (Giles 

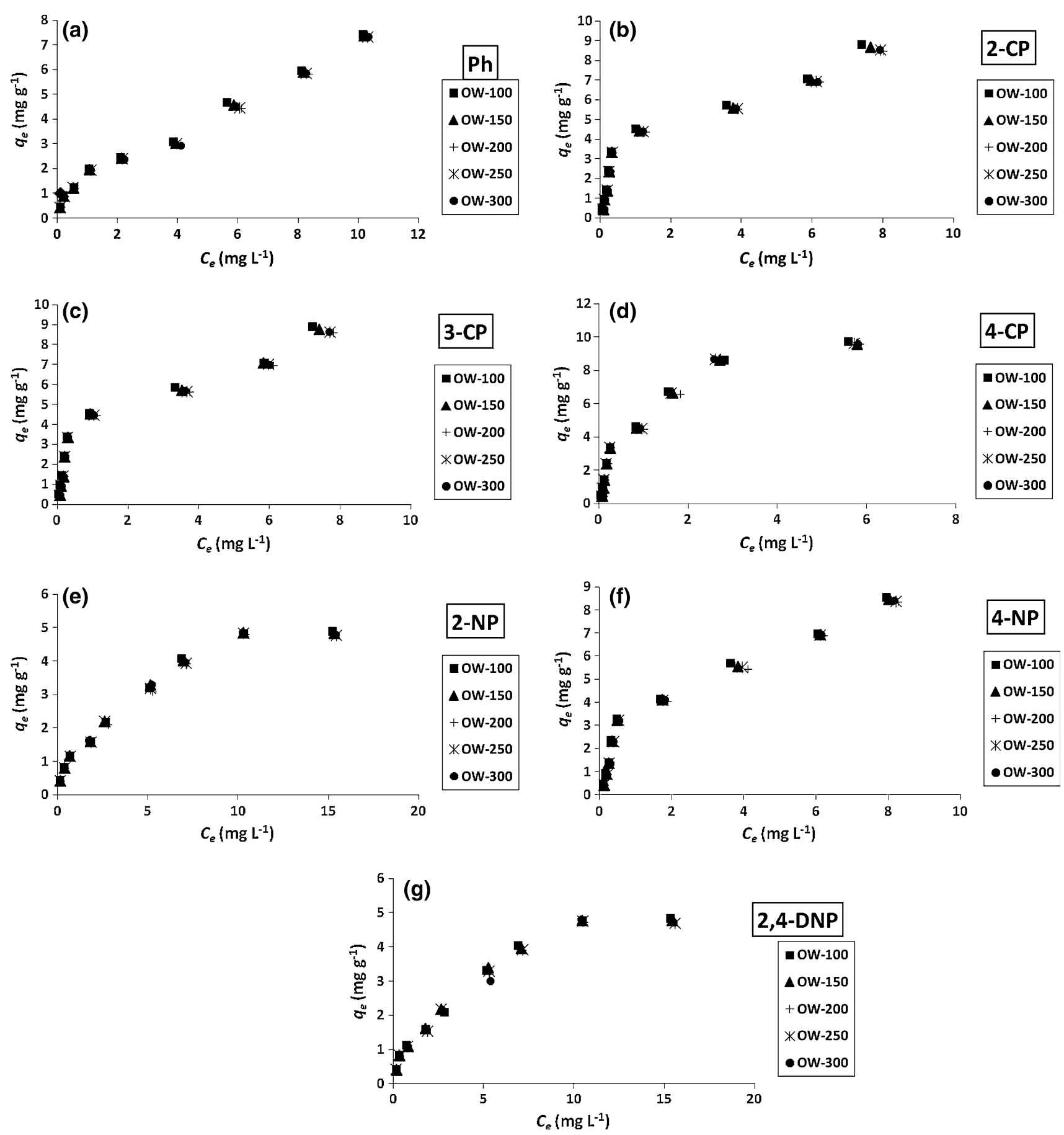

Fig. 2 Adsorption isotherms of various phenolic compounds on pyrolyzed olive wood adsorbents. a Ph; b 2-CP; c 3-CP; d 4-CP; e 2-NP; f 4-NP; g 2,4-DNP

and Smith 1974). L3-shape was the case for Ph on unpyrolyzed and pyrolyzed olive wood; H3-shape was the case for 2-CP, 3-CP and 4-NP on pyrolyzed olive wood.

Kinetic considerations

Adsorption of all the phenolic compounds on unpyrolyzed and pyrolyzed olive wood followed second-order rate equation (see Table 3 ) in terms of high $R^{2}$ and agreement between $q_{\mathrm{e}(\exp )}$ and $q_{\mathrm{e} \text { (calculated) }}$. The first-order rate law was not satisfactorily obeyed. Cruz et al. (2004) reported that the first-order adsorption kinetics is usually found within the first $30-50$ min of the adsorption process. According to MorrisWeber equation, by plotting $q_{\mathrm{e}}$ versus $t^{0.5}$, biphasic plots, which do not pass through the origin, were observed (see Fig. 4). Three steps are taking place in the sorption process: 

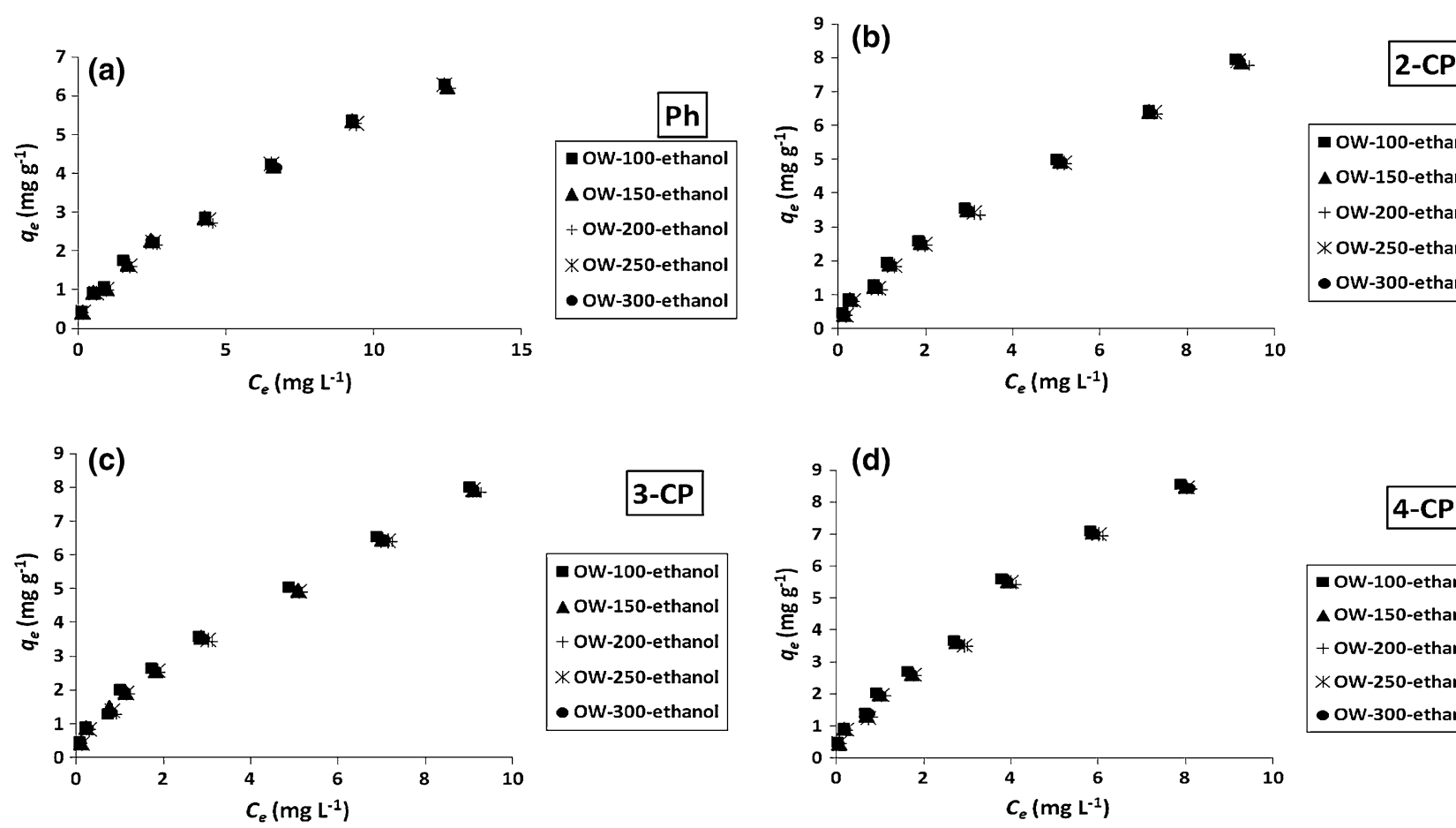

- OW-100-ethanol

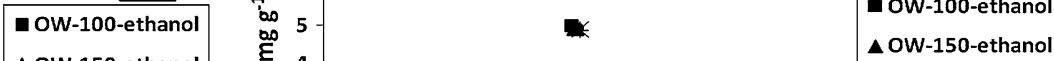

$\Delta$ OW-150-ethanol

+ OW-200-ethanol

* OW-250-ethanol

- OW-300-ethanol

+ OW-200-ethanol

*ow-250-ethanol

- ow-300-ethanol
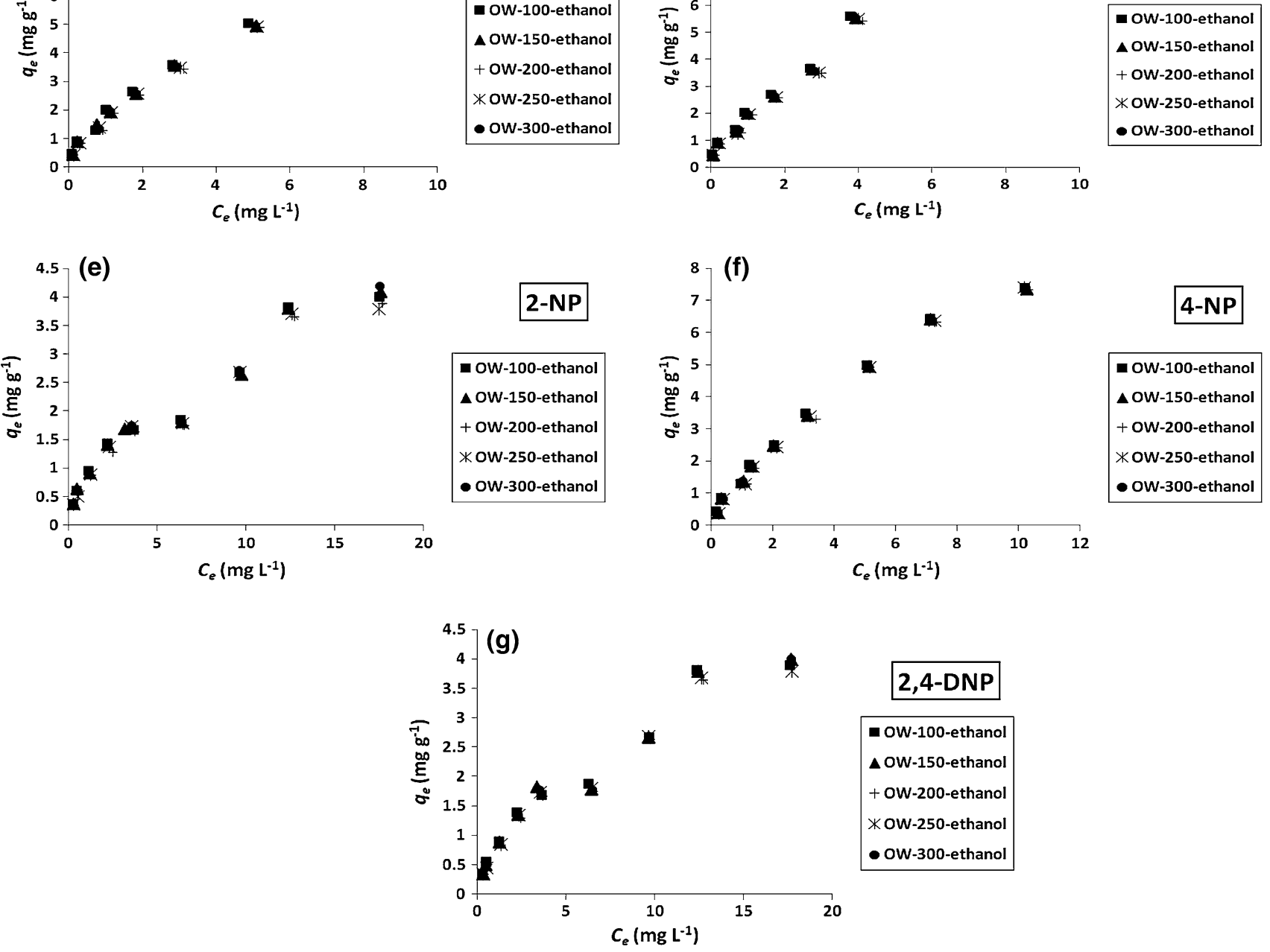

\section{2,4-DNP}

now-100-ethanol

$\Delta$ OW-150-ethanol

+ OW-200-ethanol

* ow-250-ethanol

- OW-300-ethanol

$C_{e}\left(\mathrm{mg} \mathrm{L}^{-1}\right)$

Fig. 3 Adsorption isotherms of various phenolic compounds on pyrolyzed-then-ethanol-washed olive wood adsorbents. a Ph; b 2-CP; c 3-CP; d 4-CP; e 2-NP; f 4-NP; g 2,4-DNP

first by film diffusion, then by intraparticle diffusion (pore diffusion), and then equilibrium was reached. Since a linear relationship between $q_{\mathrm{e}}$ and $t^{1 / 2}$ was observed over a period of time but did not pass through the origin, this suggested that intraparticle diffusion was present but not the only controlling step. From Table 3, it was noted that, compared to unpyrolyzed olive wood, $k_{2}$ increased for $\mathrm{Ph}, 2-\mathrm{NP}$ and 4-CP but decreased for 2-CP, 3-CP, 4-NP and 2,4-DNP. The intraparticle diffusion parameter $\left(k_{\mathrm{id}}\right)$ has decreased for all phenolic compounds except for $\mathrm{Ph}$ (see Table 1). This indicated that pyrolysis of olive wood slowed down the pore diffusion, and thus, it had more effect as a rate-limiting step. 
Table 3 Parameters of adsorption kinetics and thermodynamics of various phenols on unpyrolyzed and pyrolyzed olive wood sorbents

\begin{tabular}{|c|c|c|c|c|c|c|c|c|}
\hline & \multirow[t]{2}{*}{$\Delta S^{\circ}\left(\mathrm{J} \mathrm{K}^{-1} \mathrm{~mol}^{-1}\right)$} & \multirow[t]{2}{*}{$\Delta H^{\circ}\left(\mathrm{kJ} \mathrm{mol}^{-1}\right)$} & \multicolumn{3}{|c|}{$\Delta G^{\circ}\left(\mathrm{kJ} \mathrm{mol}^{-1}\right)$} & \multirow[t]{2}{*}{$k_{\text {id }}\left(\mathrm{g} \mathrm{mg}^{-1} \min ^{-0.5}\right)$} & \multicolumn{2}{|l|}{ Second order } \\
\hline & & & $30^{\circ} \mathrm{C}$ & $50{ }^{\circ} \mathrm{C}$ & $70{ }^{\circ} \mathrm{C}$ & & $k_{2}\left(\times 10^{-3}\right)\left(\mathrm{g} \mathrm{mg}^{-1} \mathrm{~min}^{-1}\right)$ & $R^{2}$ \\
\hline \multicolumn{9}{|l|}{$\mathrm{Ph}$} \\
\hline Unpyrolyzed & -133.7 & -46.7 & -5.7 & -2.6 & -0.2 & 0.16 & 2.1 & 0.9990 \\
\hline OW-100 & -72.1 & -27.0 & -5.4 & -3.1 & -2.6 & 0.28 & 6.9 & 0.9999 \\
\hline OW-150 & -90.2 & -32.9 & -6.0 & -2.9 & -2.5 & 0.26 & 3.8 & 0.9977 \\
\hline OW-200 & -53.8 & -21.2 & -5.4 & -2.6 & -3.4 & 0.30 & 3.8 & 0.9999 \\
\hline OW-250 & -86.0 & -31.1 & -5.3 & -2.8 & -2 & 0.36 & 7.1 & 1.0000 \\
\hline OW-300 & -89.2 & -32.2 & -5.4 & -2.7 & -1.9 & 0.32 & 3.3 & 0.9993 \\
\hline \multicolumn{9}{|l|}{$2-\mathrm{CP}$} \\
\hline Unpyrolyzed & 37.0 & 9.5 & -1.7 & -5.7 & -3.5 & 0.42 & 8.8 & 0.9995 \\
\hline OW-100 & -11.6 & -11.9 & -6.8 & -11.9 & -5.8 & 0.20 & 1.5 & 0.9415 \\
\hline OW-150 & -12.9 & -12.0 & -6.6 & -11.3 & -5.6 & 0.18 & 2.8 & 0.9983 \\
\hline OW-200 & -14.8 & -12.0 & -6.2 & -10.4 & -5.2 & 0.30 & 6.0 & 0.9995 \\
\hline OW-250 & -21.6 & -14.8 & -6.6 & -11.5 & -5.3 & 0.28 & 3.3 & 0.9963 \\
\hline OW-300 & -33.2 & -18.7 & -7.3 & -10.9 & -5.6 & 0.24 & 1.8 & 0.9832 \\
\hline \multicolumn{9}{|l|}{$3-\mathrm{CP}$} \\
\hline Unpyrolyzed & -111.9 & -38.0 & -5.3 & -2.1 & -0.8 & 0.42 & 8.6 & 0.9991 \\
\hline OW-100 & -181.0 & -65.3 & -10.7 & -6.3 & -3.6 & 0.24 & 3.9 & 0.9998 \\
\hline OW-150 & -168.1 & -61.1 & -10.3 & -6.7 & -3.6 & 0.14 & 3.6 & 0.9985 \\
\hline OW-200 & -165.8 & -60.0 & -9.8 & -6.2 & -3.2 & 0.12 & 2.8 & 0.9979 \\
\hline OW-250 & -189.2 & -68.0 & -10.8 & -6.5 & -3.3 & 0.14 & 3.1 & 0.9977 \\
\hline OW-300 & -172.5 & -62.5 & -10.4 & -6.2 & -3.6 & 0.14 & 2.5 & 0.8975 \\
\hline \multicolumn{9}{|l|}{$4-\mathrm{CP}$} \\
\hline Unpyrolyzed & -116.1 & -41.5 & -5.5 & -2.4 & -0.6 & 0.44 & 3.3 & 0.9993 \\
\hline OW-100 & -198.6 & -70.6 & -10.8 & -5.5 & -3.0 & 0.32 & 8.3 & 0.9998 \\
\hline OW-150 & -238.1 & -83.5 & -12.1 & -5.1 & -2.7 & 0.22 & 3.1 & 0.9985 \\
\hline OW-200 & -188.0 & -66.4 & -9.9 & -4.6 & -2.5 & 0.32 & 3.5 & 0.9997 \\
\hline OW-250 & -219.6 & -77.2 & -11.3 & -5.0 & -2.6 & 0.30 & 8.9 & 0.9996 \\
\hline OW-300 & -242.9 & -85.0 & -12.1 & -5.0 & -2.5 & 0.26 & 3.8 & 0.9993 \\
\hline \multicolumn{9}{|l|}{ 2-NP } \\
\hline Unpyrolyzed & -98.0 & -33.5 & -3.0 & -1.2 & 0.9 & 0.40 & 4.3 & 0.9989 \\
\hline OW-100 & -78.3 & -28.3 & -4.5 & -3.1 & -1.4 & 0.16 & 6.6 & 0.9997 \\
\hline OW-150 & -81.9 & -29.6 & -4.7 & -3.4 & -1.4 & 0.14 & 3.1 & 0.9849 \\
\hline OW-200 & -115 & -39.8 & -5.0 & -2.7 & -0.4 & 0.22 & 5.8 & 0.9995 \\
\hline OW-250 & -71.9 & -26.2 & -4.5 & -2.9 & -1.6 & 0.22 & 5.5 & 0.9997 \\
\hline OW-300 & -74.9 & -27.5 & -4.9 & -3.0 & -1.9 & 0.28 & 5.3 & 0.9996 \\
\hline \multicolumn{9}{|l|}{ 4-NP } \\
\hline Unpyrolyzed & -87.2 & -28.7 & -3.5 & -1.6 & -0.6 & 0.38 & 6.6 & 0.9989 \\
\hline OW-100 & -177.8 & -64.2 & -10.7 & -5.9 & -3.7 & 0.16 & 1.9 & 0.9904 \\
\hline OW-150 & -172.5 & -62.4 & -10.4 & -6.2 & -3.5 & 0.20 & 3.2 & 0.9956 \\
\hline OW-200 & -142.6 & -51.6 & -8.6 & -5.0 & -2.9 & 0.20 & 2.0 & 0.9935 \\
\hline OW-250 & -142.5 & -52.7 & -9.7 & -6.3 & -4.0 & 0.20 & 2.5 & 0.9910 \\
\hline OW-300 & -178.4 & -65.0 & -11.2 & -6.9 & -4.2 & 0.18 & 2.1 & 0.9983 \\
\hline \multicolumn{9}{|l|}{ 2,4-DNP } \\
\hline Unpyrolyzed & -48.1 & -19.2 & -3.5 & -2.3 & -1.9 & 0.30 & 4.7 & 0.9991 \\
\hline OW-100 & -82.2 & -30.0 & -4.9 & -3.9 & -1.5 & 0.24 & 1.5 & 0.9631 \\
\hline OW-150 & -94.1 & -33.8 & -5.2 & -3.6 & -1.4 & 0.26 & 3.4 & 0.9984 \\
\hline
\end{tabular}


Table 3 continued

\begin{tabular}{|c|c|c|c|c|c|c|c|c|}
\hline & \multirow[t]{2}{*}{$\Delta S^{\circ}\left(\mathrm{J} \mathrm{K}^{-1} \mathrm{~mol}^{-1}\right)$} & \multirow[t]{2}{*}{$\Delta H^{\circ}\left(\mathrm{kJ} \mathrm{mol}^{-1}\right)$} & \multicolumn{3}{|c|}{$\Delta G^{\circ}\left(\mathrm{kJ} \mathrm{mol}^{-1}\right)$} & \multirow[t]{2}{*}{$k_{\text {id }}\left(\mathrm{g} \mathrm{mg}^{-1} \min ^{-0.5}\right)$} & \multicolumn{2}{|l|}{ Second order } \\
\hline & & & $30^{\circ} \mathrm{C}$ & $50{ }^{\circ} \mathrm{C}$ & $70^{\circ} \mathrm{C}$ & & $\overline{k_{2}\left(\times 10^{-3}\right)\left(\mathrm{g} \mathrm{mg}^{-1} \mathrm{~min}^{-1}\right)}$ & $R^{2}$ \\
\hline OW-200 & -98.0 & -34.6 & -4.8 & -3.2 & -0.9 & 0.30 & 2.6 & 0.7675 \\
\hline OW-250 & -71.4 & -26.4 & -4.7 & -3.7 & -1.8 & 0.20 & 4.0 & 0.9994 \\
\hline OW-300 & -71.3 & -26.5 & -4.9 & -3.6 & -2.0 & 0.26 & 4.7 & 0.9997 \\
\hline
\end{tabular}
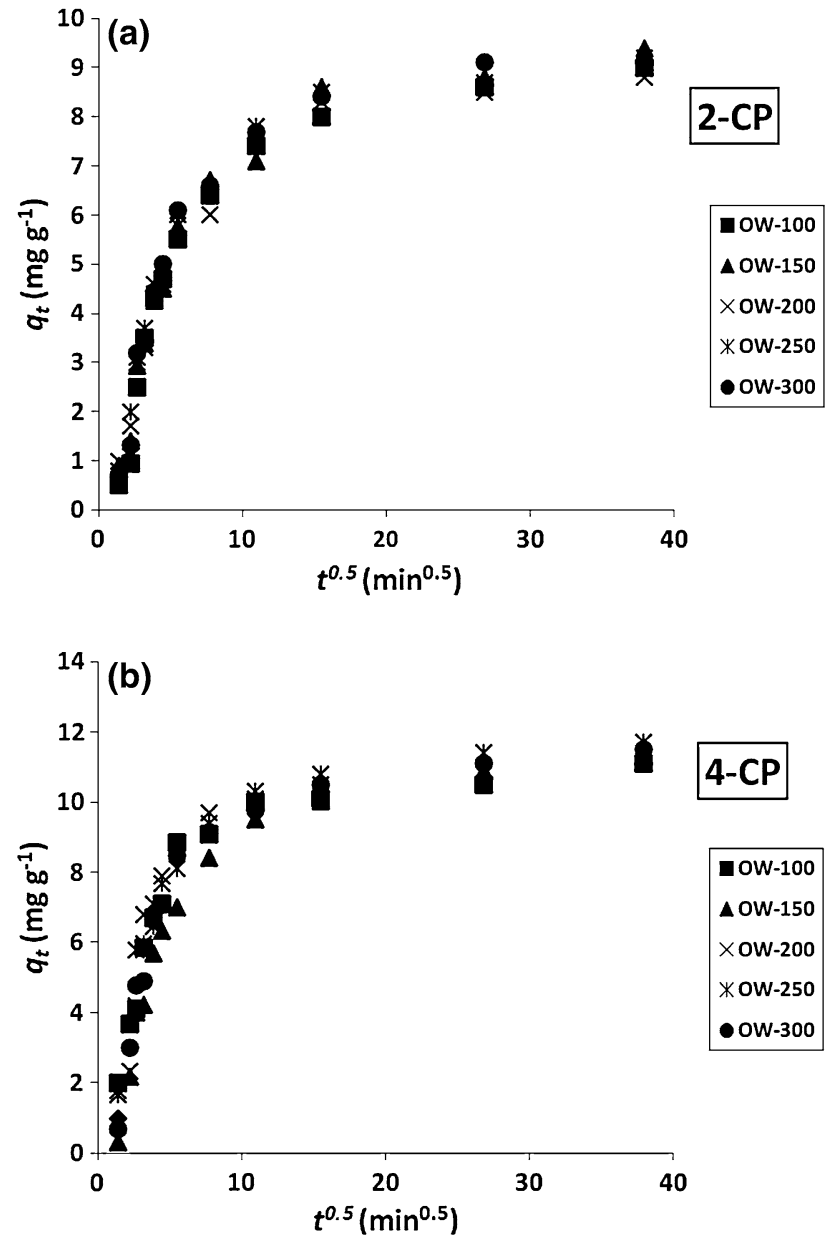

Fig. 4 Intraparticle diffusion plots for the adsorption of a 2-CP and b 4-CP on pyrolyzed olive wood adsorbents

The values of $k_{\mathrm{id}}$ of the pyrolyzed olive wood were very close to those values reported by Aravindhan et al. (2009) for the adsorption of phenol on green macro-alga, and those reported by $\mathrm{Wu}$ and $\mathrm{Yu}$ (2006) for the adsorption of 2,4-dichlorophenol on Phanerochaete chrysosporium.

The kinetic parameters for the adsorption of phenols pyrolyzed-then-ethanol-washed sorbents are shown in Table 4. It was noted that, compared to the pyrolyzed only olive wood sorbents, $k_{2}$ decreased for $\mathrm{Ph}$ and 2-NP but increased for 2-CP, 3-CP, 4-CP, 4-NP and 2,4-DNP.
According to the Morris-Weber equation, the pyrolyzedthen-ethanol-washed sorbents gave higher $k_{\text {id }}$ values for all phenols (except $\mathrm{Ph}$ ), which indicated that the intraparticle diffusion step became faster and thus has a less effect as a rate-limiting step.

Thermodynamic considerations

According to the thermodynamic parameters presented in Table 3, adsorption of phenols on unpyrolyzed olive wood was generally exothermic as indicated by negative $\Delta H^{\circ}$ values. The adsorption process was spontaneous at $30^{\circ} \mathrm{C}$, but the spontaneity of the adsorption decreases at higher temperatures as indicated by $\Delta G^{\circ}$ values that became less negative. The randomness decreased after adsorption as indicated by the negative values of $\Delta S^{\circ}$.

The effect of pyrolysis of olive wood on its adsorption thermodynamic parameters toward various phenols is shown in Table 3. The results were compared with the unpyrolyzed olive wood sorbent. It was noted that $\ln K_{c}$ (which represent the favorability, capacity and ability of the adsorbent to retain adsorbate) increased for all the phenols at all the temperatures. Consequently, the spontaneity of the reaction (expressed by the increase in negativity of $\Delta G^{\circ}$ values) has increased for all the phenols. The values of $\Delta G^{\circ}$ lie within the physical adsorption range (from -20 to $0 \mathrm{~kJ} \mathrm{~mol}^{-1}$ ). The adsorption process became more exothermic for all the phenols after pyrolysis except for $\mathrm{Ph}$. This was indicated by the negative increase in $\Delta H^{\circ}$ values. The randomness of the adsorption process increased for $\mathrm{Ph}$ and 2-NP. This was reflected by the increase in $\Delta S^{\circ}$ values. On the contrary, the randomness of the adsorption process decreased for 2-CP, 3-CP, 4-CP, 4-NP and 2,4-DNP.

Thermodynamic parameters for the pyrolyzed-ethanolwashed olive wood are presented in Table 4. Compared to the pyrolyzed only olive wood sorbents, it was noted that adsorption became less spontaneous as indicated by less negative $\Delta G^{\circ}$ values. Furthermore, less negative $\Delta H^{\circ}$ values indicated less exothermic adsorption for the phenolic compounds after washing the pyrolyzed olive wood sorbents (except for $\mathrm{Ph}$ ). By following $\Delta S^{\circ}$ values, it was noted that the randomness of the adsorption process increased for all the phenols except for Ph. 
Table 4 Parameters of adsorption kinetics and thermodynamics of pyrolyzed-ethanol-washed olive wood sorbents

\begin{tabular}{|c|c|c|c|c|c|c|c|c|}
\hline & \multirow[t]{2}{*}{$\Delta S^{\circ}\left(\mathrm{J} \mathrm{K}^{-1} \mathrm{~mol}^{-1}\right)$} & \multirow[t]{2}{*}{$\Delta H^{\circ}\left(\mathrm{kJ} \mathrm{mol}^{-1}\right)$} & \multicolumn{3}{|c|}{$\Delta G^{\circ}\left(\mathrm{kJ} \mathrm{mol}^{-1}\right)$} & \multirow[t]{2}{*}{$k_{\mathrm{id}}\left(\mathrm{g} \mathrm{mg}^{-1} \min ^{-0.5}\right)$} & \multicolumn{2}{|l|}{ Second order } \\
\hline & & & $30^{\circ} \mathrm{C}$ & $50^{\circ} \mathrm{C}$ & $70^{\circ} \mathrm{C}$ & & $\begin{array}{l}k_{2}\left(\times 10^{-3}\right) \\
\left(\mathrm{g} \mathrm{mg}^{-1} \min ^{-1}\right)\end{array}$ & $R^{2}$ \\
\hline \multicolumn{9}{|l|}{$\mathrm{Ph}$} \\
\hline OW-100-ethanol & -107.5 & -37.4 & -4.7 & -2.9 & -0.3 & 0.26 & 2.2 & 0.9990 \\
\hline OW-150-ethanol & -103.3 & -35.8 & -4.3 & -2.8 & -0.1 & 0.16 & 1.9 & 0.9990 \\
\hline OW-200-ethanol & -106.5 & -36.1 & -3.9 & -1.5 & 0.3 & 0.28 & 2.8 & 0.9991 \\
\hline OW-250-ethanol & -89.9 & -30.8 & -3.7 & -1.4 & -0.2 & 0.14 & 1.5 & 0.9964 \\
\hline OW-300-ethanol & -115.0 & -39.4 & -4.7 & -1.8 & -0.1 & 0.20 & 2.1 & 0.9970 \\
\hline \multicolumn{9}{|l|}{ 2-CP } \\
\hline OW-100-ethanol & 23.1 & 2.5 & -3.8 & -6.6 & -4.5 & 0.46 & 7.7 & 0.9998 \\
\hline OW-150-ethanol & 22.0 & 2.5 & -3.5 & -6.3 & -4.1 & 0.56 & 6.3 & 0.9997 \\
\hline OW-200-ethanol & 2.7 & -3.0 & -3.0 & -5.7 & -2.9 & 0.56 & 4.2 & 0.9998 \\
\hline OW-250-ethanol & 16.9 & 1.1 & -3.3 & -5.9 & -3.8 & 0.42 & 9.1 & 0.9998 \\
\hline OW-300-ethanol & 11.6 & -0.9 & -3.8 & -6.1 & -4.1 & 0.38 & 10.9 & 0.9998 \\
\hline \multicolumn{9}{|l|}{ 3-CP } \\
\hline OW-100-ethanol & -119.0 & -42.2 & -6.3 & -3.3 & -1.6 & 0.16 & 6.7 & 0.9994 \\
\hline OW-150-ethanol & -104.2 & -36.9 & -5.6 & -2.6 & -1.5 & 0.20 & 8.7 & 0.9958 \\
\hline OW-200-ethanol & -115.1 & -40.1 & -5.4 & -2.3 & -0.9 & 0.18 & 4.1 & 0.9956 \\
\hline OW-250-ethanol & -88.4 & -31.7 & -5.3 & -2.4 & -1.8 & 0.16 & 4.4 & 0.9991 \\
\hline OW-300-ethanol & -92.0 & -33.2 & -5.6 & -2.7 & -2.1 & 0.26 & 6.7 & 0.9921 \\
\hline \multicolumn{9}{|l|}{ 4-CP } \\
\hline OW-100-ethanol & -115.3 & -40.2 & -5.4 & -2.6 & -0.8 & 0.48 & 8.8 & 0.9999 \\
\hline OW-150-ethanol & -114.3 & -39.8 & -5.3 & -2.5 & -0.7 & 0.44 & 23.2 & 1.0000 \\
\hline OW-200-ethanol & -114.4 & -39.4 & -4.8 & -2.1 & -0.3 & 0.40 & 2.4 & 0.9895 \\
\hline OW-250-ethanol & -104.5 & -36.6 & -5.1 & -2.4 & -1.0 & 0.38 & 10.2 & 0.9999 \\
\hline OW-300-ethanol & -123.7 & -43.2 & -5.9 & -2.9 & -1.1 & 0.38 & 8.0 & 0.9998 \\
\hline \multicolumn{9}{|l|}{ 2-NP } \\
\hline OW-100-ethanol & -73.1 & -26.6 & -4.3 & -3.4 & -1.3 & 0.22 & 3.9 & 0.9987 \\
\hline OW-150-ethanol & -75.5 & -27.2 & -4.2 & -3.2 & -1.1 & 0.28 & 3.8 & 0.9989 \\
\hline OW-200-ethanol & -69.9 & -24.3 & -3.1 & -1.9 & -0.2 & 0.34 & 4.1 & 0.9994 \\
\hline OW-250-ethanol & -80.5 & -28.3 & -3.8 & -2.5 & -0.6 & 0.26 & 2.6 & 0.9927 \\
\hline OW-300-ethanol & -79.6 & -28.2 & -3.9 & -2.9 & -0.7 & 0.38 & 5.3 & 0.9991 \\
\hline \multicolumn{9}{|l|}{$4-\mathrm{NP}$} \\
\hline OW-100-ethanol & -119.8 & -41.5 & -5.4 & -2.4 & -0.6 & 0.48 & 9.9 & 0.9999 \\
\hline OW-150-ethanol & -110.8 & -37.8 & -4.4 & -1.7 & -0.1 & 0.50 & 24.5 & 1.0000 \\
\hline OW-200-ethanol & -111.8 & -37.8 & -4.0 & -1.5 & 0.4 .0 & 0.46 & 8.0 & 0.9999 \\
\hline OW-250-ethanol & -115.5 & -39.9 & -4.9 & -2.4 & -0.3 & 0.44 & 7.9 & 0.9999 \\
\hline OW-300-ethanol & -111.0 & -38.2 & -4.7 & -2.2 & -0.3 & 0.38 & 8.0 & 0.9998 \\
\hline \multicolumn{9}{|l|}{ 2,4-DNP } \\
\hline OW-100-ethanol & -54.8 & -20.8 & -4.2 & -2.8 & -2.1 & 0.32 & 10.3 & 0.9999 \\
\hline OW-150-ethanol & -69.8 & -25.3 & -4.2 & -2.7 & -1.5 & 0.16 & 3.2 & 0.9987 \\
\hline OW-200-ethanol & -66.6 & -23.5 & -3.5 & -1.5 & -0.8 & 0.22 & 3.8 & 0.9963 \\
\hline OW-250-ethanol & -69.4 & -24.7 & -3.8 & -1.9 & -1.0 & 0.24 & 5.3 & 0.9993 \\
\hline OW-300-ethanol & -61.1 & -22.1 & -3.7 & -2.0 & -1.3 & 0.24 & 4.6 & 0.9993 \\
\hline
\end{tabular}

\section{Conclusion}

Pyrolysis of olive wood has positively affected adsorption capacity, favorability and spontaneity of phenolic compounds on the pyrolyzed olive wood. The temperature of pyrolysis did not show any clear trend on the adsorption properties. Washing the pyrolyzed sorbents with ethanol has negatively affected the adsorption capacity, favorability and spontaneity. This 
indicated that pyrolysis produced species on the surface that were responsible for the improved adsorption properties of the pyrolyzed olive wood. While this paper is important in its own right, the authors wish to make suggestions for further work. In particular, the authors feel that the process needs investigating in a scaled up form. Future experiments might include an investigation of the effects of different pyrolysis techniques; for example, partial pyrolysis before the grinding might be equally effective and, in practice, might make the required grinding process less demanding of energy. It is also worthy to investigate how the partial pyrolysis might be achieved to provide sorbents for use in real water treatment situations.

Acknowledgments The authors are grateful for the Faculty of Graduate Studies and Scientific Research at the Hashemite University for supporting this project.

\section{References}

Abia AA, Horsfall M, Didi O (2003) The use of chemically modified and unmodified cassava waste for the removal of $\mathrm{Cd}, \mathrm{Cu}$ and $\mathrm{Zn}$ ions from aqueous solution. Bioresour Technol 90:345-348

Ahmaruzzaman M (2008) Adsorption of phenolic compounds on lowcost adsorbents: a review. Adv Colloid Interface 143:48-67

Aravindhan R, Rao JR, Nair BU (2009) Application of a chemically modified green macro alga as a biosorbent for phenol removal. J Environ Manag 90:1877-1883

Bansode RR, Losso JN, Marshall WE, Rao RM, Portier RJ (2004) Pecan shell-based granular activated carbon for treatment of chemical oxygen demand (COD) in municipal wastewater. Bioresour Technol 94:129-135

Bayramoglu G, Gursel I, Tunali Y, Arica MY (2009) Biosorption of phenol and 2-chlorophenol by Funalia trogii pellets. Bioresour Technol 100:2685-2691

Brandt S, Zen AP, Deckwer WD (1997) Adsorption and desorption of pentachlorophenol on cells of Mycobacterium chlorophenolicum PCP-1. Biotechnol Bioeng 55:480-489

Bridgwater AV (1994) Thermogravimetric analysis of the components of biomass: advances in thermochemical biomass conversion. Blackie Academic and Professional, London

Cruz CCV, Da Costa ACA, Henriques CA, Luna AS (2004) Kinetic modeling and equilibrium studies during cadmium biosorption by dead Sargassum sp. Biomass. Bioresour Technol 91:249-257

de Hoces MC, de Castro FH, Garcia GB, Rivas G (2006) Equilibrium modeling of removal of cadmium ions by olive stones. Environ Prog 25:261-266

El-Sheikh AH, Newman AP, Al-Daffaee H, Phull S, Cresswell N (2004) Characterization of activated carbon prepared from a single cultivar of Jordanian olive stone by chemical and physicochemical techniques. J Anal Appl Pyrol 71:151-164

El-Sheikh AH, Alzawahreh AM, Sweileh JA (2011) Preparation of an efficient sorbent by washing then pyrolysis of olive wood for simultaneous solid phase extraction of chloro-phenols and nitrophenols from water. Talanta 85:1034-1042

Fourest E, Volesky B (1997) Alginate properties and heavy metal biosorption by marine algae. Appl Biochem Biotechnol 67:215-226

Freundlich HMF (1906) Liber die adsorption in lösungen. Phys Chem $57: 385-470$

Frimmel FH, Huber L (1996) Influence of humic substances on the aquatic sorption of heavy metals on defined minerals phases. Environ Int 22:507-517
Giles CH, Smith DA (1974) General treatment and classification of the solute sorption isotherms. J Colloid Interface 47:755-765

Grioui N, Halouani K, Zoulalian A, Halouani F (2007) Experimental study of thermal effect on olive wood porous structure during carbonization. Maderas Ciencia y tecnología 9:15-28

Hajaligol M, Waymack B, Kellogg D (2002) Pyrolysis behaviour and kinetics of biomass derived materials. J Anal Appl Pyrol 62:331-349

Ho YS, McKay G (2000) The kinetics of sorption of divalent metal ions onto sphagnum moss peat. Water Res 34:735-742

Igwe JC, Nwokennaya EC, Abia AA (2005) The role of pH in heavy metal detoxification by biosorption from aqueous solutions containing chelating agents. Afr J Biotechnol 4:1109-1112

Khan AR, Singh RP (1987) Adsorption thermodynamics of carbofuran on $\mathrm{Sn}(\mathrm{IV})$ arsenosilicate in $\mathrm{H}^{+}, \mathrm{Na}^{+}$and $\mathrm{Ca}^{2+}$ forms. Colloid Surface A 24:33-42

Lagergren S (1898) Zur theorie der sogenannten adsorption geloester stoffe. K Sven Vetenskapsakad Handl 24:1-39

Langmuir I (1918) The adsorption of gases on plane surfaces of glass, mica, and platinum. JACS 40:1361-1368

Martin-Lara MA, Pagnanelli F, Mainelli S, Calero M, Toro L (2008) Chemical treatment of olive pomace: effect on acid-base properties and metal biosorption capacity. J Hazard Mater 156:448-457

Mathialagan T, Viraraghavan T (2008) Biosorption of chlorophenols: a review. Int J Environ Pollut 34:164-194

Nadavala SK, Swayampakula K, Boddu VM, Abburi K (2009) Biosorption of phenol and $o$-chlorophenol from aqueous solutions on to chitosan-calcium alginate blended beads. J Hazard Mater 162:482-489

Navarro AE, Portales RF, Sun-Kou MR, Llanos BP (2008) Effect of $\mathrm{pH}$ on phenol biosorption by marine seaweeds. J Hazard Mater 156:405-411

Overend RP, Chornet E (1999) 4th conference on biomass: a growth opportunity in green energy and value-added products. Pergamon-Elsevier Science, Oxford

Pan B, Xing B (2008) Adsorption mechanisms of chemicals on carbon nanotubes. Environ Sci Technol 42:9005-9013

Perez-Bonilla M, Salido S, van Beek TA, Linares-Palomino PJ, Altarejos J, Nogueras M, Sanchez A (2006) Isolation and identification of radical scavengers in olive tree (Olea europaea) wood. J Chromatogr A 1112:311-318

Raji C, Amirudhan TS (1998) Batch Cr(VI) removal by polyacrylamide-grafted saw dust: kinetics and thermodynamics. Water Res 32:3772-3780

Saka C, Sahin O, Küçük MM (2012) Applications on agricultural and forest waste adsorbents for the removal of lead (II) from contaminated waters. Int J Environ Sci Technol 9:379-394

Sanchez AG, Ayuso EA, De Blas OJ (1999) Sorption of heavy metals from industrial waste water by low-cost mineral silicates. Clay Miner 34:469-477

Shin EW, Karthikeyan KG, Tshabalala MA (2005) Orthophosphate sorption onto lanthanum-treated lignocellulosic sorbents. Environ Sci Technol 39:6273-6279

US Environmental Protection Agency (1988) Technology screening guide for treatment of CERCLA soils and sludges. Publication EPA/540/2-88/004, Washington DC

Vazquez G, Gonzalez-Alvarez J, Garcia AI, Freire MS, Antorrena G (2007) Adsorption of phenol on formaldehyde-pretreated Pinus pinaster bark: equilibrium and kinetics. Bioresour Technol 98:1535-1540

Weber WJ, Morris JC (1963) Kinetics of adsorption on carbon from solution. J Sanit Eng Div 89:31-39

Wu J, Yu H (2006) Biosorption of 2,4-dichlorophenol from aqueous solution by Phanerochaete chrysosporium biomass: isotherms, kinetics and thermodynamics. J Hazard Mater 137:498-508

Zghida H, Gauthier R, Helal A, Bartegi A (2006) Modeling of adsorption of anionic surfactants onto cationized lignocellulosic materials. J Appl Polym Sci 99:82-87 